\title{
A meta-analysis for comparison of partial nephrectomy vs. radical nephrectomy in patients with pT3a renal cell carcinoma
}

\author{
Hui Liu ${ }^{1}$, Qing-Fang Kong ${ }^{2 \#}$, Jian Li ${ }^{3 \#}$, Yu-Qing Wu ${ }^{4 \#}$, Ke-Hao Pan ${ }^{1}$, Bin Xu ${ }^{1}$, Ya-Li Wang ${ }^{1}$, Ming Chen $^{1}$ \\ ${ }^{1}$ Department of Urology, Binhai People's Hospital, Yancheng, China; ${ }^{2}$ Department of Nosocomial Infection, Affiliated Zhongda Hospital of \\ Southeast University, Nanjing, China; ${ }^{3}$ Department of Urology, Jinhu People's Hospital, Jinhu, China; ${ }^{4}$ Zhongda Hospital of Southeast University, \\ Southeast University, Lishui District People's Hospital, Nanjing, China \\ Contributions: (I) Conception and design: All authors; (II) Administrative support: L Hui, QF Kong, KH Pan, B Xu, YL Wang, M Chen; (III) \\ Provision of study materials or patients: L Hui, QF Kong, KH Pan, B Xu, YL Wang, M Chen; (IV) Collection and assembly of data: L Hui, \\ QF Kong, KH Pan, B Xu, YL Wang, M Chen; (V) Data analysis and interpretation: L Hui, QF Kong, KH Pan, B Xu, YL Wang, M Chen; (VI) \\ Manuscript writing: All authors; (VII) Final approval of manuscript: All authors. \\ \#These authors contributed equally to this work as the co-second author. \\ Correspondence to: Ke-Hao Pan; Bin Xu, MD; Ya-Li Wang; Ming Chen, MD. Department of Urology, Affiliated Zhongda Hospital of Southeast \\ University, Lishui District People's Hospital, 87 Dingjia Bridge Hunan Road, Nanjing 210009, China. Email: pankehao0319@163.com; \\ xb15896450810@126.com; 15150666260@163.com; mingchenseu@126.com.
}

Background: Kidney cancer is the most common malignant tumor of the kidney in adults. However, in terms of the treatment for pT3a renal cell carcinoma (RCC), whether partial nephrectomy (PN) can be selected is still controversial. This study was conducted to compare the efficacy of PN and radical nephrectomy $(\mathrm{RN})$ in treatment for patients with pT3a RCC.

Methods: The relative English databases including PubMed and EMBASE were searched for studies comparing PN and RN for pT3a RCC between 2010 and 2020. Stata 13.0 software was used to compare the cancer-specific survival (CSS), overall survival (OS), cancer-specific mortality (CSM), relapse-free survival (RFS), complications and positive surgical margin.

Results: Nine articles were included with a total of 3,391 patients, of whom 2,113 received RN and 1,278 received PN. The results showed that there is no statistical difference in CSS, OS, CSM, RFS, complications and positive surgical margin between RN and PN. No heterogeneity was shown in study.

Conclusions: There were no differences in the CSS, OS, CSM, RFS, complications and positive surgical margin of the patients in RN and PN group. For pT3a RCC, RN did not provide a better survival benefit compared to $\mathrm{PN}$. Considering $\mathrm{PN}$ can suppress the progression of tumor and reduce the risk of postoperative chronic renal insufficiency, we found PN is a good choice for pT3a RCC. However, further large-sample, studies are still needed in future.

Keywords: Radical nephrectomy (RN); partial nephrectomy (PN); survival; pT3a renal cell carcinoma (pT3a RCC); meta-analysis

Submitted Sep 12, 2020. Accepted for publication Jan 22, 2021.

doi: $10.21037 /$ tau-20-1262

View this article at: http://dx.doi.org/10.21037/tau-20-1262

\section{Introduction}

Kidney cancer is the most common malignant tumor of the kidney in adults, accounting for $2 \%$ to $3 \%$ of adult malignant tumors (1). At present, the incidence of kidney cancer is increasing at a rate of about $2 \%$ per year, which is the lethal tumor among urinary tract tumors. The Union for International Cancer Control (UICC) tumor-nodemetastasis (TNM) classification system classifies tumors 
with perirenal fat invasion (PFI), renal sinus fat invasion (SFI), or renal vein invasion (RVI) as stage pT3a (2). This advanced disease state is typically aggressive with 5 -year disease-free survival rates ranging from $30 \%$ to $85 \%(3,4)$, including a median time to recurrence ranging from 11 to 22 months (5-8). Surgery is the first choice for the treatment of kidney cancer, and also the only way to cure. $\mathrm{RN}$ is considered the "gold standard" for the treatment of localized renal cancer. With the continuous development of medical technology, the tumor control effect of $\mathrm{PN}$ is the same as that of RN (9-13), and it can preserve renal function and improve the quality of life of patients after surgery. It has become the new standard for the treatment of stage T1a renal cancer (14). However, for pT3a renal cell carcinoma (RCC), whether PN can be selected is still controversial.

The aim of this study was to compare the survival outcomes in patients with $\mathrm{RN}$ or PN. This study aims to provide evidence for $\mathrm{pT} 3 \mathrm{a}$ RCC in the clinic through metaanalysis. We present the following article in accordance with the PRISMA reporting checklist (available at http:// dx.doi.org/10.21037/tau-20-1262).

\section{Methods}

\section{Document retrieval}

Databases including PubMed and EMBASE were searched for studies from 2010 to 2020. The keywords used were as follow: partial nephrectomy, radical nephrectomy, survival and pT3a RCC. Professional search style was used to search for related references manually.

\section{Study selection}

Exclusion criteria: (I) duplicates; (II) absence of specific data; (III) case, case reports, reviews; (IV) patients with a history of other tumors.

\section{Literature screening}

Literature was independently screened by two reviewers based on the inclusion criteria, first screening the title and abstract. Then the full text of the documents was read to include the studies that may meet the inclusion criteria. After cross-checking the results, data were extracted from cohort studies. A unified table was used to record the information of each study, including the first author, publication year, research design, general case information, tumor size, surgery approach and data of cancer-specific survival (CSS), overall survival (OS) and cancer-specific mortality (CSM).

\section{Literature quality evaluation}

Modified Newcastle-Ottawa Scale (NOS) was used to evaluate the quality of the included documents. The scale consists of three large blocks, including: selection of research populations, comparability between groups and exposure evaluation or result evaluation. NOS uses a semi-quantitative star system to evaluate the quality of the literature, with a perfect score of nine stars. Two researchers evaluated each study independently.

\section{Statistical analysis}

This research used statistical software Stata13.0 to merge data. The data of CSS, OS, CSM, relapse-free survival (RFS), complications and positive surgical margin were extracted for analysis. Between-study statistical heterogeneity was assessed using $\mathrm{I}^{2}$ and the Cochrane $\mathrm{Q}$ test. If the studies are homogeneous $\left(\mathrm{P}>0.10, \mathrm{I}^{2}<50 \%\right)$, it is considered that there is no heterogeneity in the included literature, and the fixedeffect model is used (15). Counting data was analyzed by rate ratio (RR). The significance level was set to $\alpha=0.05$, and $95 \%$ confidence interval $(95 \% \mathrm{CI})$ was taken. The funnel plot was drawn and the symmetry of the funnel was tested by linear regression to detect the publication bias (16).

\section{Results}

\section{Features of included literature}

According to the inclusion and exclusion criteria, a total of nine articles were included in this study (17-25) (Figure 1). The characteristics of the studies are showed in Table 1.

A total of 3,391 patients were included, including 1,278 patients in the PN group, 2,113 patients in the $\mathrm{RN}$ group. Among the nine studies, two of them compared the tumor-specific survival rates between $\mathrm{RN}$ and $\mathrm{PN}$ group $(19,22)$, five studies compared OS rates (18-22), two studies compared CSM $(17,20)$, three studies compared RFS $(18,23,24)$, three studies compared complications $(20,22,25)$ and five studies compared positive surgical margin (18,20,22-24). The baseline characteristics of included studies were shown in Table 2.

\section{Qualitative analysis}

The quality of the articles included was satisfactory. The 


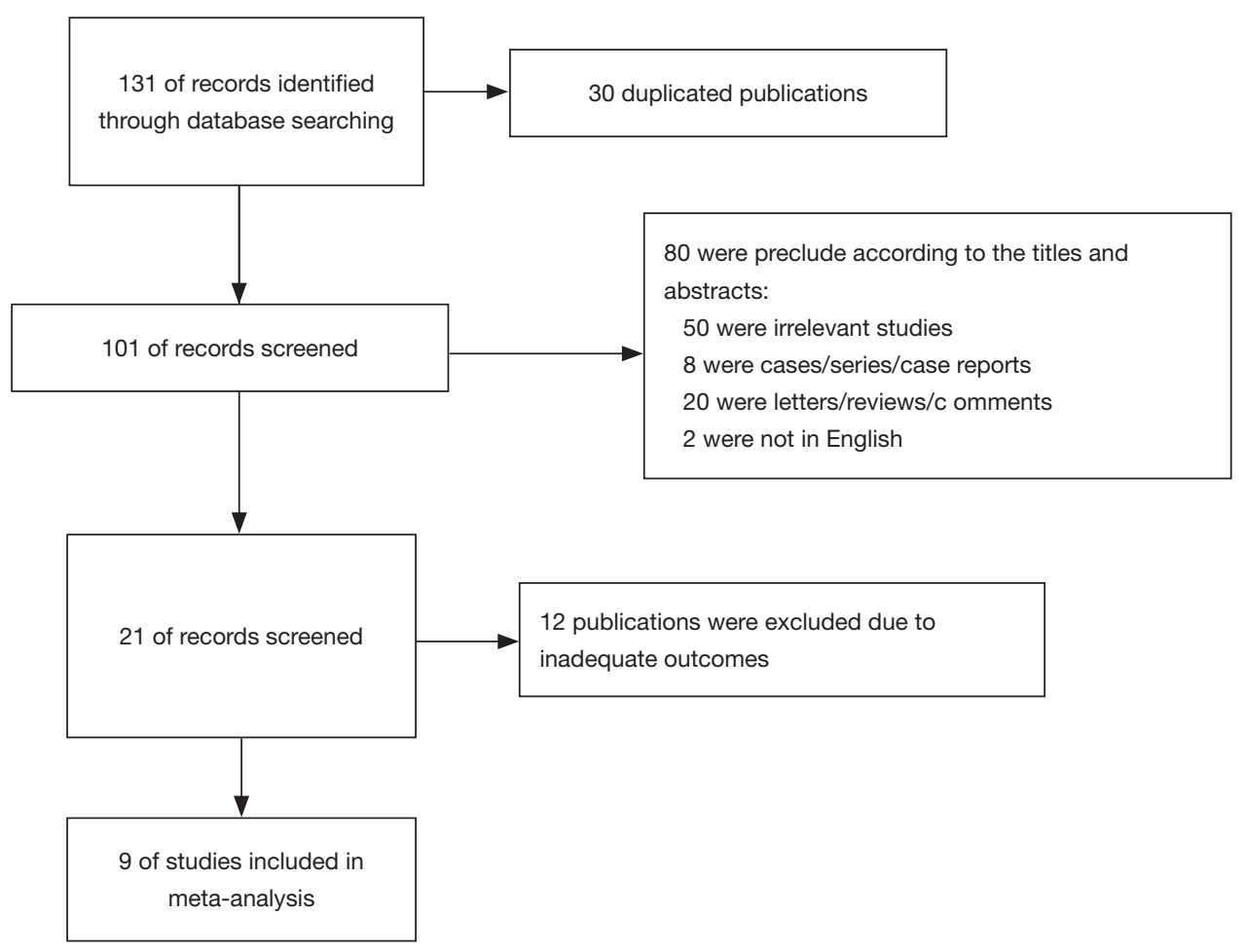

Figure 1 Flowchart of study selection.

research quality evaluation is shown in Table 3.

\section{Meta-analysis}

\section{CSS}

No heterogeneity was found among the studies comparing the tumor-specific survival rates $\left(\mathrm{I}^{2}=0 \%, \mathrm{P}=0.38\right)$, and the fixed-effects model was used for combined analysis. No statistically significant difference was found in tumorspecific survival rate between $\mathrm{PN}$ and RN groups (RR: 1.02, 95\% CI: 0.97-1.97) (Figure 2).

\section{OS}

Six studies involved OS. The $\mathrm{I}^{2}=55 \%(\mathrm{P}=0.05)$ indicated that there was no heterogeneity and the fixed-effects model was utilized. The combined RR of these studies were RR: 1.04, $95 \%$ CI: $(0.96,1.11)$ (Figure 3) and there is no statistical difference.

\section{CSM}

Two studies involved CSM. There is no heterogeneity among the studies $\left(\mathrm{I}^{2}=0 \%, \mathrm{P}=0.72\right)$, and the fixed-effects model is used for combined analysis. No statistically significant difference was found in CSM rate between RN and PN groups (RR: 1.00, 95\% CI: 0.72-1.41) (Figure 4).

\section{RFS}

Three studies involved RFS. No statistically significant difference was found in RFS rate between RN and PN groups (RR: 0.93, 95\% CI: 0.75-1.16) (Figure 5).

\section{Complications}

Three studies reported complications, including secondary bleeding and wound infection. No statistically significant difference was found in complications between $\mathrm{RN}$ and $\mathrm{PN}$ groups (RR: 0.78, 95\% CI: 0.50-1.23) (Figure 6).

\section{Positive surgical margin}

Five studies reported positive surgical margin. No statistically significant difference was found in positive surgical margin between RN and PN groups (RR: 1.05, 95\% CI: 0.78-1.41) (Figure 7).

\section{Publication bias}

Funnel plots were used for the test of publication bias, and 
Table 1 Basic situation of nine documents

\begin{tabular}{llllll}
\hline Studies & Year & Size & Study type & Intervention & Outcome quality score; age; EENAL score \\
\hline Hansen (17) & 2012 & 954 & Retrospective & RN, PN & CSM 7; 64; NA \\
Hamilton (18) & 2020 & 360 & Retrospective & RN, PN & RFS, OS 8; 60.7; RN: 7.8, PN: 7.7 \\
Weight (19) & 2011 & 203 & Retrospective & RN, PN & CSS, OS 8; 64; NA \\
Patel (20) & 2020 & 929 & Retrospective & RN, PN & CSM, OS 7; 63; RN: 8.81, PN: 9.9 \\
Ziegelmueller (21) & 2019 & 55 & Retrospective & RN, PN & OS 8; 67.9; RN: 7.3, PN: 7.3 \\
Andrade (22) & 2017 & 140 & Retrospective & RN, PN & CSS, OS 8; 62.4; RN: 8, PN: 8 \\
Patel (23) & 2017 & 501 & Retrospective & RN, PN & RFS 7; 63.2; NA \\
Jeong (24) & 2016 & 91 & Retrospective & RN, PN & RFS 8; 58.6; RN: 7.5, PN: 7.6 \\
Mühlbauer (25) & 2020 & 158 & Retrospective & RN, PN & OS 9; 67.0; RN: 10, PN: 8 \\
\hline
\end{tabular}

RN, radical nephrectomy; PN, partial nephrectomy; CSM, cancer-specific mortality; RFS, relapse-free survival; OS, overall survival; CSS, cancer-specific survival.

Table 2 Features of included studies

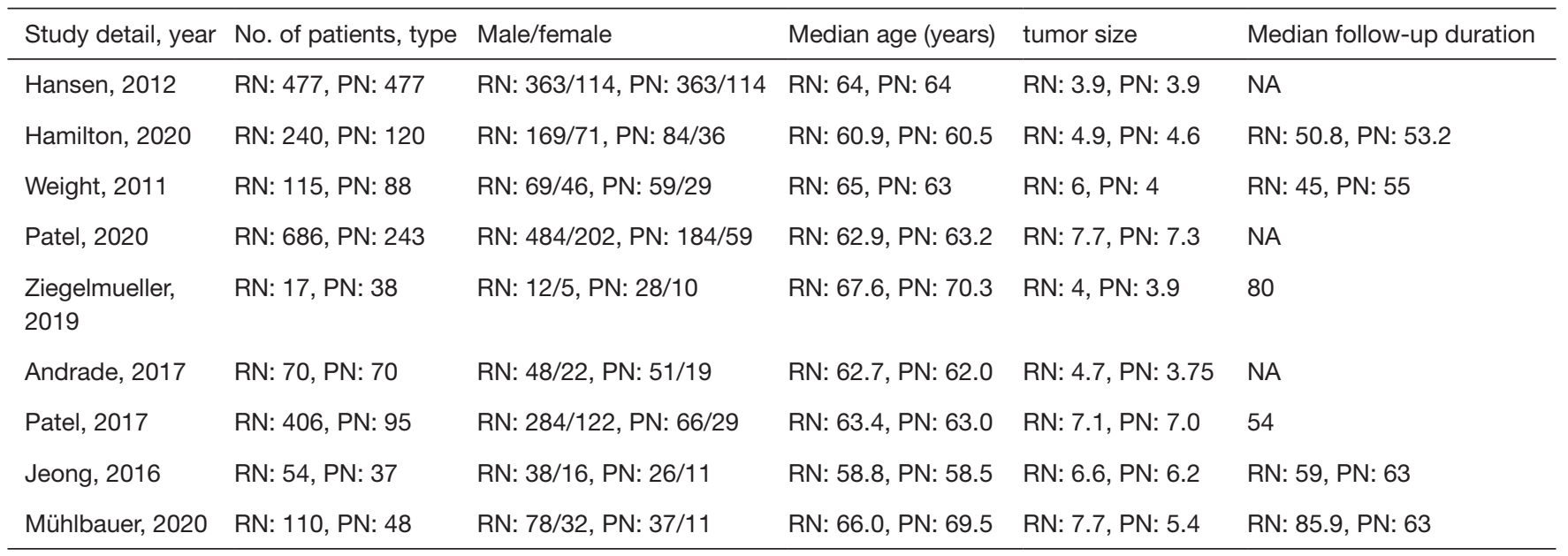

$\mathrm{RN}$, radical nephrectomy; PN, partial nephrectomy.

Table 3 Quality assessment of included studies (the modified NOS)

\begin{tabular}{lll}
\hline Selection of patients & Comparability of groups & Evaluation of the treatment outcome \\
\hline 3 & 2 & 2 \\
2 & 3 & 3 \\
3 & 2 & 3 \\
3 & 2 & 2 \\
3 & 3 & 3 \\
3 & 2 & 3 \\
3 & 3 & 2 \\
3 & 2 & 2 \\
\hline
\end{tabular}

NOS, Newcastle-Ottawa Scale. 


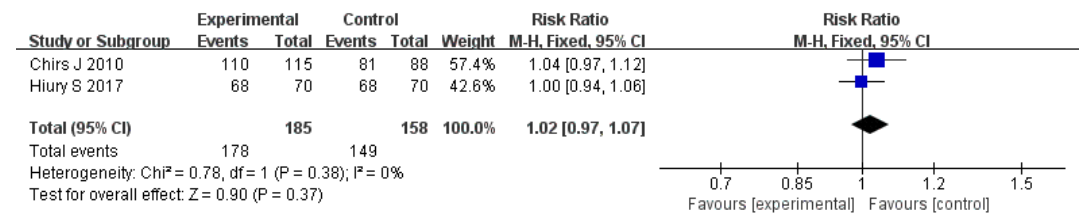

Figure 2 Forest plot of CSS rates between PN and RN. CSS, cancer-specific survival; RN, radical nephrectomy; PN, partial nephrectomy.

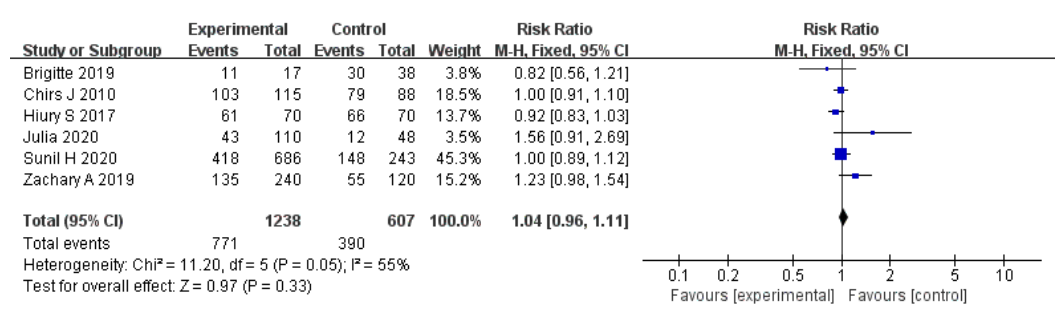

Figure 3 Forest plot of OS rates between PN and RN. OS, overall survival; RN, radical nephrectomy; PN, partial nephrectomy.

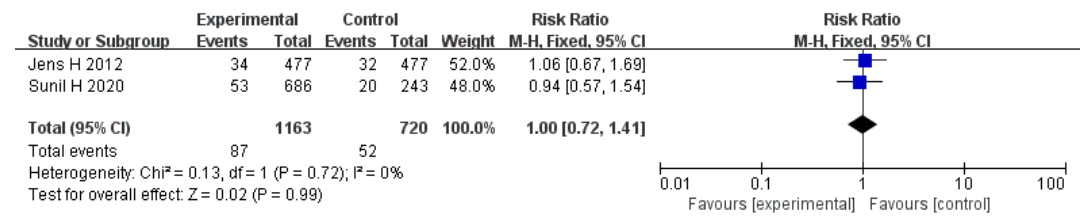

Figure 4 Forest plot of CSM rates between PN and RN. CSM, cancer-specific mortality; RN, radical nephrectomy; PN, partial nephrectomy.

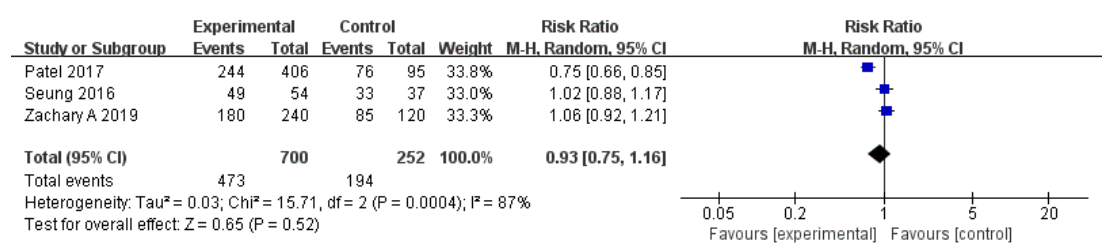

Figure 5 Forest plot of RFS rates between PN and RN. RFS, relapse-free survival; RN, radical nephrectomy; PN, partial nephrectomy.

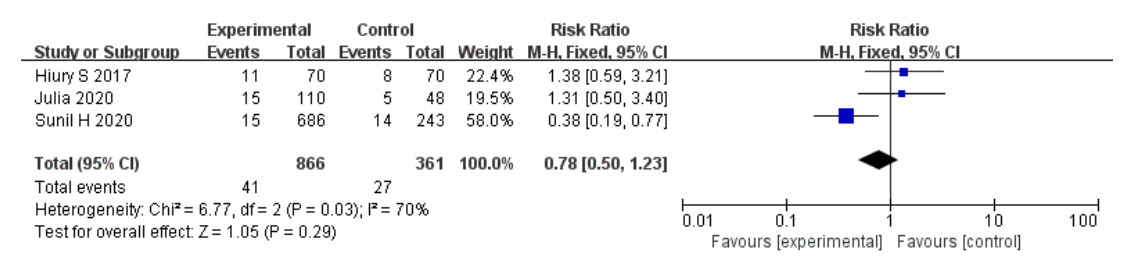

Figure 6 Forest plot of complication between PN and RN. RN, radical nephrectomy; PN, partial nephrectomy. 


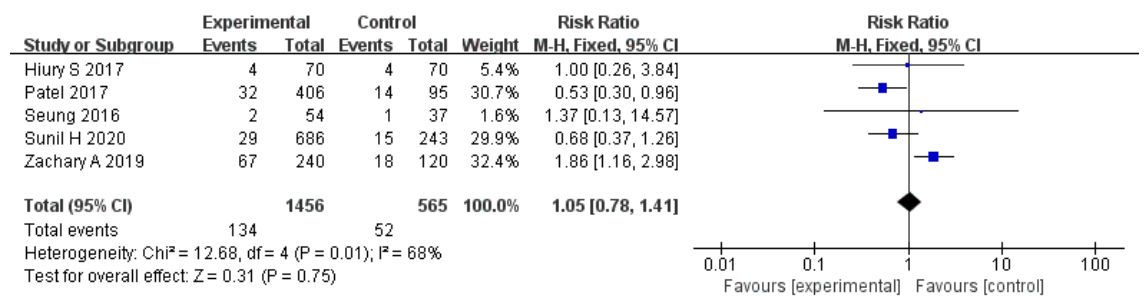

Figure 7 Forest plot of positive surgical margin between PN and RN. RN, radical nephrectomy; PN, partial nephrectomy.

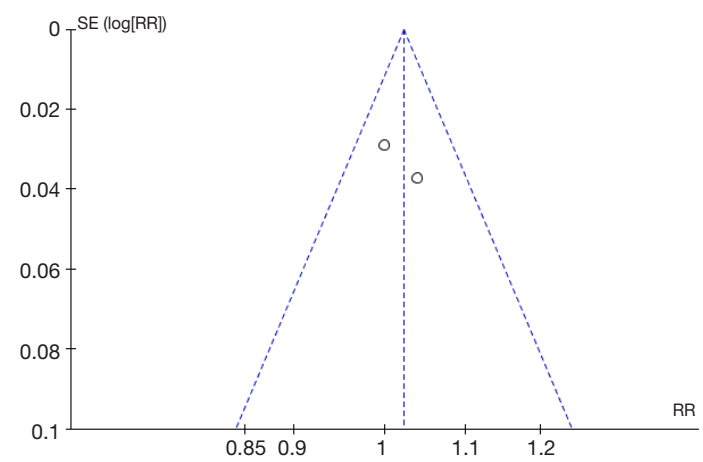

Figure 8 Publication bias funnel chart of CSS. CSS, cancerspecific survival.

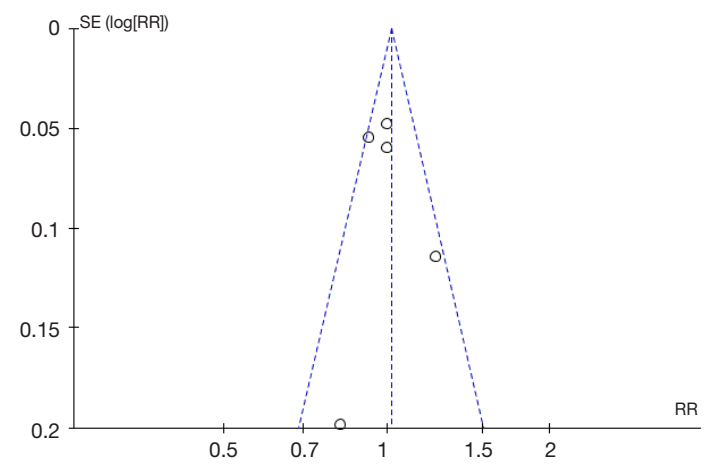

Figure 9 Publication bias funnel chart of OS. OS, overall survival.

the results were shown from Figures 8-13.

\section{Discussion}

PN for the management of T1a tumors has evolved during the last two decades, which may become the standard care for T1b tumors as well, demonstrating oncological safety and renal function preservation (26). PN is already an established and widely adopted approach for the surgical treatment of renal masses (27), and contemporary studies

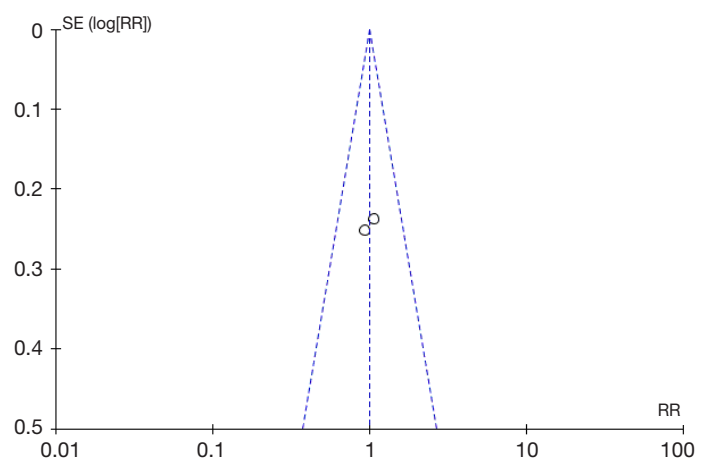

Figure 10 Publication bias funnel chart of CSM. CSM, cancerspecific mortality.

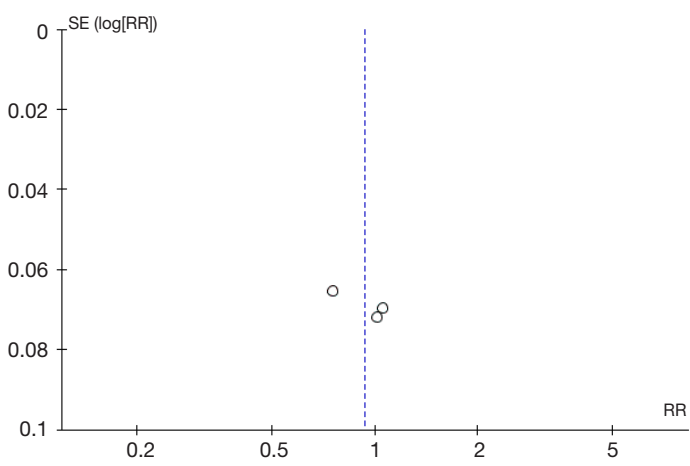

Figure 11 Publication bias funnel chart of RFS. RFS, relapse-free survival.

have demonstrated its feasibility in more complex cases with the growing experience with this technique (28-30). Nonetheless, PN is still a challenging technique for the treatment pT3a tumors and its utility in this setting warrants further debates. In this study, we compared the survival outcomes of patients with pT3a tumors who underwent $\mathrm{PN}$ with those treated by $\mathrm{RN}$.

The safety of PN for T3a tumors has already been addressed in some studies, most of them suggesting 


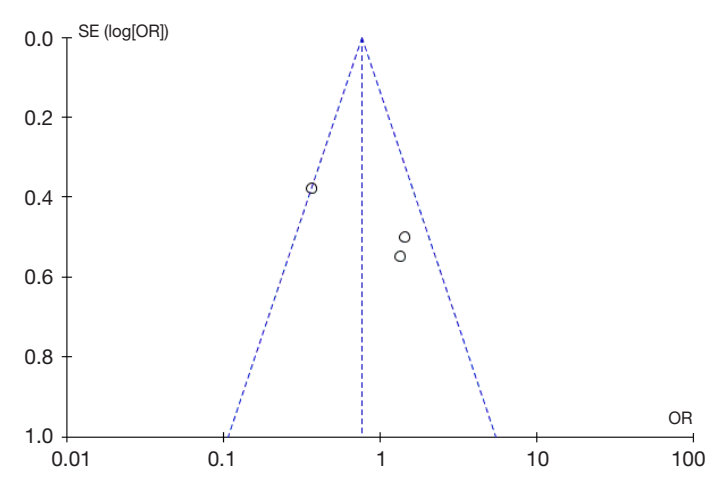

Figure 12 Publication bias funnel chart of complication.

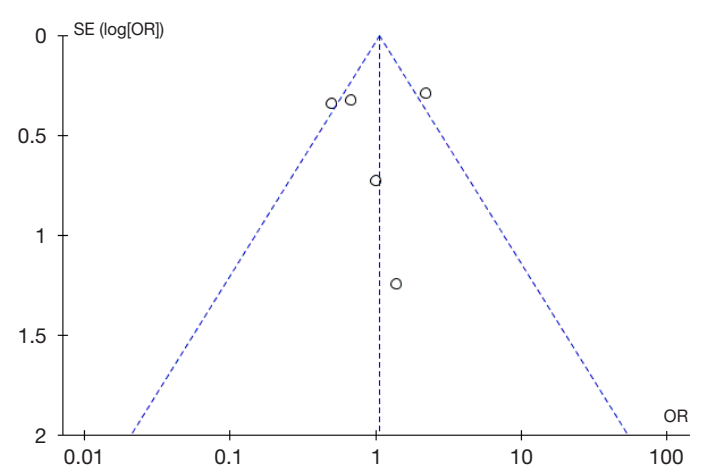

Figure 13 Publication bias funnel chart of positive surgical margin.

equivalent oncological outcomes when comparing PN with RN. However, these studies included all types of surgical modalities, incorporated cases with aggressive tumors characteristics other than pathological T3a, or used prior T3a classification. In a recent multi-institutional study, Oh and colleagues (31) demonstrated that PN had lower recurrence rate comparable with $\mathrm{RN}$ in the subset pathological T3a and supported the notion that, for selected cases, PN is a safe treatment even in the face of adverse pathological findings.

Similarly, Weight et al. (19) noted no difference in OS for $\mathrm{RN}$ versus $\mathrm{PN}$ in pT3a patients. In recent years, it has been reported that $\mathrm{PN}$ not only can control the tumor progression, but also reduces the risk of postoperative chronic renal insufficiency and improves the long-term quality of life. However, the renal blood vessels are rich and the tissue is relatively brittle. The vascular end of the surgical wound of the kidney may form a pseudoaneurysm, arteriovenous fistula, etc., resulting in renal hematoma or hematuria after surgery. At present, there are relatively few reports on local recurrence after PN, but PN does not clearly indicate whether resection of the affected kidney is more likely to cause tumor recurrence and metastasis. From the perspective of underestimated risk of tumor margin positive, risk of serious complications and tumor control, we must pay attention to the high risk of PN. Bertolo (32) assessed the role of three-dimensional (3D) reconstruction in aiding preoperative planning for highly complex renal tumors amenable to robotic partial nephrectomy (RPN). After viewing the respective $3 \mathrm{D}$ reconstructions, in 148 cases the responders changed their idea: indication to RPN raised in 404 cases $(74.5 \%)(\mathrm{P}<0.001)$. The use of this technology might translate into a larger adoption of nephron-sparing approach, and more advanced technologies are needed in the future. Hansen (17) made a regression analysis of patients with tumor size $>7.0 \mathrm{~cm}$ and found tumor size had no statistical significance to the survival outcomes [hazard ratio (HR): $0.67,95 \%$ CI: $0.30-2.17]$. Therefore, the outcomes of pT3a tumors could apply to cT3a tumors.

Our study had some limitations. First, the analysis of heterogeneity sources required more subgroup data. Second, the diagnostic criteria were inconsistent in the studies. Finally, this only nine studies were included in this analysis, more studies are still needed in future.

There were no differences in the CSS, OS, CSM, RFS, complications and positive surgical margin of the patients between $\mathrm{RN}$ and $\mathrm{PN}$ group. In pT3a RCC, RN did not provide a better survival benefit compared to $\mathrm{PN}$. Considering $\mathrm{PN}$ has a good tumor control effect and can reduce the risk of postoperative chronic renal insufficiency, we suggest a universal application of PN for pT3a RCC.

\section{Conclusions}

There were no differences in the CSS, OS, CSM, RFS, complications and positive surgical margin of the patients between $\mathrm{RN}$ and $\mathrm{PN}$ group. In pT3a RCC, RN did not provide a better survival benefit compared to $\mathrm{PN}$. Considering $\mathrm{PN}$ has a good tumor control effect and can reduce the risk of postoperative chronic renal insufficiency, we found PN is a good choice for pT3a RCC. PN for pT3 is a challenge for surgeons and requires experience. In the future, further large-sample, studies are needed.

\section{Acknowledgments}

We have invited Ms. Yu-Qing Wu to polish our language. Funding: This study was funded by the National Natural 
Science Foundation of China (No. 81872089, 81370849, 81672551, 81300472, 81070592, 81202268, 81202034), Natural Science Foundation of Jiangsu Province (BK20161434, BL2013032, BK20150642 and BK2012336), Six Talent Peaks Project in Jiangsu Province, Jiangsu Provincial Medical Innovation Team (CXTDA2017025), the National Key Research and Development Program of China (SQ2017YFSF090096), Jiangsu Provincial Key Research and Development Program (BE2019751), Innovative Team of Jiangsu Provincial (2017ZXKJQWO7), Jiangsu Provincial Medical Talent (ZDRCA2016080).

\section{Footnote}

Reporting Checklist: The authors have completed the PRISMA reporting checklist. Available at http://dx.doi.org/10.21037/ tau-20-1262

Peer Review File: Available at http://dx.doi.org/10.21037/tau20-1262

Conflicts of Interest: All authors have completed the ICMJE uniform disclosure form (available at http://dx.doi. org/10.21037/tau-20-1262). The authors have no conflicts of interest to declare.

Ethical Statement: The authors are accountable for all aspects of the work in ensuring that questions related to the accuracy or integrity of any part of the work are appropriately investigated and resolved.

Open Access Statement: This is an Open Access article distributed in accordance with the Creative Commons Attribution-NonCommercial-NoDerivs 4.0 International License (CC BY-NC-ND 4.0), which permits the noncommercial replication and distribution of the article with the strict proviso that no changes or edits are made and the original work is properly cited (including links to both the formal publication through the relevant DOI and the license). See: https://creativecommons.org/licenses/by-nc-nd/4.0/.

\section{References}

1. Miller KD, Siegel RL, Lin CC, et al. Cancer treatment and survivorship statistics, 2016. CA Cancer J Clin 2016;66:271-89.

2. Zhang $\mathrm{Z}$, Yu $\mathrm{C}$, Velet $\mathrm{L}$, et al. The difference in prognosis between renal sinus fat and perinephric fat invasion for
pT3a renal cell carcinoma: a meta-analysis. PLoS One 2016;11:e0149420.

3. Stewart GD, Ang WJ, Laird A, et al. The operative safety and oncological outcomes of laparoscopic nephrectomy for T3 renal cell cancer. BJU Int 2012;110:884-90.

4. Bansal RK, Tu HY, Drachenberg D, et al. Laparoscopic management of advanced renal cell carcinoma with renal vein and inferior vena cava thrombus. Urology 2014;83:812-6.

5. Gofrit ON, Shapiro A, Kovalski N, et al. Renal cell carcinoma: evaluation of the 1997 TNM system and recommendations for follow-up after surgery. Eur Urol 2001;39:669-74; discussion 675.

6. Stephenson AJ, Chetner MP, Rourke K, et al. Guidelines for the surveillance of localized renal cell carcinoma based on the patterns of relapse after nephrectomy. J Urol 2004;172:58-62.

7. Levy DA, Slaton JW, Swanson DA, et al. Stage specific guidelines for surveillance after radical nephrectomy for local renal cell carcinoma. J Urol 1998;159:1163-7.

8. Lam JS, Shvarts O, Leppert JT, et al. Postoperative surveillance protocol for patients with localized and locally advanced renal cell carcinoma based on a validated prognostic nomogram and risk group stratification system. J Urol 2005;174:466-72; discussion 472; quiz 801.

9. Campbell S, Uzzo RG, Allaf ME, et al. Renal mass and localized renal cancer: AUA Guideline. J Urol 2017;198:520-9.

10. Ljungberg B, Albiges L, Abu-Ghanem Y, et al. European Association of Urology Guidelines on renal cell carcinoma: the 2019 update. Eur Urol 2019;75:799-810.

11. Finelli A, Ismaila N, Bro B, et al. Management of small renal masses: American Society of Clinical Oncology Clinical Practice Guideline. J Clin Oncol 2017;35:668-80.

12. Kim SP, Thompson RH, Booriian SA, et al. Comparative effectiveness for survival and renal function of partial and radical nephrectomy for localized renal tumors: a systematic review and meta-analysis. J Urol 2012;188:51-7.

13. Van Poppel H, Da Pozzo L, Albrecht W, et al. A prospective, randomised EORTC intergroup phase 3 study comparing the oncologic outcome of elective nephron sparing surgery and radical nephrectomy for low-stage renal cell carcinoma. Eur Urol 2011;59:543-52.

14. Liss MA, Wang S, Palazzi K, et al. Evaluation of national trends in the utilization of partial nephrectomy in relation to the publication of the American Urologic Association guidelines for the management of clinical T1 renal masses. BMC Urol 2014;14:101. 
15. Wells G, Shea B, O'Connell D, et al. The NewcastleOttawa Scale (NOS) for assessing the quality of nonrandomised studies in meta-analysis. 2012. Available online: http://www3.med.unipmn.it/dispense_ebm/20092010/Corso\%20Perfezionamento\%20EBM_Faggiano/ NOS_oxford.pdf

16. DerSimonian R, Laird N. Meta-analysis in clinical trials. Control Clin Trials 1986;7:177-88.

17. Hansen J, Sun M, Bianchi M, et al. Assessment of cancer control outcomes in patients with high-risk renal cell carcinoma treated with partial nephrectomy. Urology 2012;80:347-53.

18. Hamilton ZA, Capitanio U, Pruthi D, et al. Risk factors for upstaging, recurrence, and mortality in clinical T1-2 renal cell carcinoma patients upstaged to $\mathrm{p} T 3$ a disease: an international analysis utilizing the 8th edition of the Tumor-Node-Metastasis Staging Criteria. Urology 2020;138:60-8.

19. Weight CJ, Lythgoe C, Unnikrishnan R, et al. Partial nephrectomy does not compromise survival in patients with pathologic upstaging to $\mathrm{pT} 2 / \mathrm{pT} 3$ or high-grade renal tumors compared with radical nephrectomy. Urology 2011;77:1142-6.

20. Patel SH, Uzzo RG, Larcher A, et al. Oncologic and functional outcomes of radical and partial nephrectomy in p'T3a pathologically upstaged renal cell carcinoma: a multi-institutional analysis. Clin Genitourin Cancer 2020;18:e723-9.

21. Ziegelmueller BK, Spek A, Szabados B, et al. Partial nephrectomy in pT3a tumors less than $7 \mathrm{~cm}$ in diameter has a superior overall survival compared to radical nephrectomy. Cureus 2019;11:e5781.

22. Andrade $\mathrm{HS}$, Zargar $\mathrm{H}, \mathrm{Akca} \mathrm{O}$, et al. Is robotic partial nephrectomy safe for T3a renal cell carcinoma? Experience of a high-volume center. J Endourol 2017;31:153-7.

23. Patel P, Nayak JG, Liu Z, et al. A multicentered, propensity matched analysis comparing laparoscopic and

Cite this article as: Liu H, Kong QF, Li J, Wu YQ, Pan KH, $\mathrm{Xu} \mathrm{B}$, Wang YL, Chen M. A meta-analysis for comparison of partial nephrectomy vs. radical nephrectomy in patients with pT3a renal cell carcinoma. Transl Androl Urol 2021;10(3):11701178. doi: 10.21037/tau-20-1262 open surgery for p T3a renal cell carcinoma. J Endourol 2017;31:645-50.

24. Jeong SH, Kim JK, Park J, et al. Pathological T3a upstaging of clinical T1 renal cell carcinoma: outcomes according to surgical technique and predictors of upstaging. PLoS One 2016;11:e0166183.

25. Mühlbauer J, Kowalewski KF, Walach MT, et al. Partial nephrectomy preserves renal function without increasing the risk of complications compared with radical nephrectomy for renal cell carcinomas of stages pT2-3a. Int J Urol 2020;27:906-13.

26. Nguyen CT, Campbell SC, Novick AC. Choice of operation for clinically localized renal tumor. Urol Clin North Am 2008;35:645-55; vii.

27. Merseburger AS, Herrmann TR, Shariat SF, et al. EAU guidelines on robotic and single-site surgery in urology. Eur Urol 2013;64:277-91.

28. Simhan J, Smaldone MC, Tsai KJ, et al. Perioperative outcomes of robotic and open partial nephrectomy for moderately and highly complex renal lesions. J Urol 2012;187:2000-4.

29. Volpe A, Garrou D, Amparore D, et al. Perioperative and renal functional outcomes of elective robot-assisted partial nephrectomy (RAPN) for renal tumours with high surgical complexity. BJU Int 2014;114:903-9.

30. Brandao LF, Zargar H, Autorino R, et al. Robot-assisted partial nephrectomy for $7 \mathrm{~cm}$ renal masses: a comparative outcome analysis. Urology 2014;84:602-8.

31. Oh JJ, Byun SS, Lee SE, et al. Partial nephrectomy versus radical nephrectomy for non-metastatic pathological T3a renal cell carcinoma: a multi-institutional comparative analysis. Int J Urol 2014;21:352-7.

32. Bertolo R, Autorino R, Fiori C, et al. Expanding the indications of robotic partial nephrectomy for highly complex renal tumors: urologists' perception of the impact of hyperaccuracy three-dimensional reconstruction. J Laparoendosc Adv Surg Tech A 2019;29:233-9. 